\title{
DEVELOPMENT OF ADDITIVE CONSTRUCTION TECHNOLOGIES FOR APPLICATION TO DEVELOPMENT OF LUNAR/MARTIAN SURFACE STRUCTURES USING IN-SITU MATERIALS
}

\author{
Niki J. Werkheiser \\ NASA/Marshall Space Flight Center \\ Building 4201, Room 204b \\ Huntsville, AL 35612 \\ Michael R. Fiske, Jennifer E. Edmunson \\ Jacobs Technologies \\ 1525 Perimeter Parkway, Ste 400, Huntsville, AL 35806 \\ Berokh Khoshnevis \\ Contour Crafting Corporation \\ 13900 Panay Way \\ Marina Del Ray, CA 90292
}

\begin{abstract}
For long-duration missions on other planetary bodies, the use of in situ materials will become increasingly critical. As human presence on these bodies expands, so must the breadth of the structures required to accommodate them including habitats, laboratories, berms, radiation shielding for natural radiation and surface reactors, garages, solar storm shelters, greenhouses, etc.

Planetary surface structure manufacturing and assembly technologies that incorporate in situ resources provide options for autonomous, affordable, pre-positioned environments with radiation shielding features and protection from micrometeorites, exhaust plume debris, and other hazards. The ability to use in situ materials to construct these structures will provide a benefit in the reduction of upmass that would otherwise make long-term Moon or Mars structures cost prohibitive. The ability to fabricate structures in situ brings with it the ability to repair these structures, which allows for the self-sufficiency and sustainability necessary for long-duration habitation.

Previously, under the auspices of the MSFC In-Situ Fabrication and Repair (ISFR) project and more recently, under the jointly-managed MSFC/KSC Additive Construction with Mobile Emplacement (ACME) project, the MSFC Surface Structures Group has been developing materials and construction technologies to support future planetary habitats with in situ resources. One such additive construction technology is known as Contour Crafting.
\end{abstract}


This paper presents the results to date of these efforts, including development of novel nozzle concepts for advanced layer deposition using this process. Conceived initially for rapid development of cementitious structures on Earth, it also lends itself exceptionally well to the automated fabrication of planetary surface structures using minimally processed regolith as aggregate, and binders developed from in situ materials as well. This process has been used successfully in the fabrication of construction elements using lunar regolith simulant and Mars regolith simulant, both with various binder materials. Future planned activities will be discussed as well.

\section{INTRODUCTION}

As the nation prepares for long-duration manned missions to Mars, asteroids, or beyond, it is apparent that the viability of these visits with appropriate environmental crew protection (radiation, thermal, meteorites) hinges on the development of planetary surface structures based primarily on in-situ materials and preferably in advance of a manned landing. These are known as Type III [1].

The Additive Construction with Mobile Emplacement (ACME) project is one element of the NASA Game Changing Development Program Advanced Manufacturing Technologies project and is part of the In-Space Manufacturing (ISM) Initiative at NASA's Marshall Space Flight Center. ACME is co-led by MSFC and Kennedy Space Center (KSC) and includes the teammates Contour Crafting Corporation (CCC), the US Army Corps of Engineers (USACE), and the Pacific International Space Center for Exploration Systems (PISCES). This paper will focus on MSFC's key areas of interest/development.

Additive Construction is a process by which a surface structure (garage, habitat, berm, wall, tower, etc) could be built in a layered fashion by controlling the deposition of cementitious material in a pre-programmed manner. One such process, known as Contour Crafting, was pioneered by Dr. Behrokh Khoshnevis of the University of Southern California (USC), and most recently of CCC. The system shown in Figure 1 is one configuration of Contour Crafting, utilizing a batch processing chamber that is fed manually. This system has proven the concept on a sub-scale, allowing the fabrication of many complex shapes, including the dome shown in Figure 2.

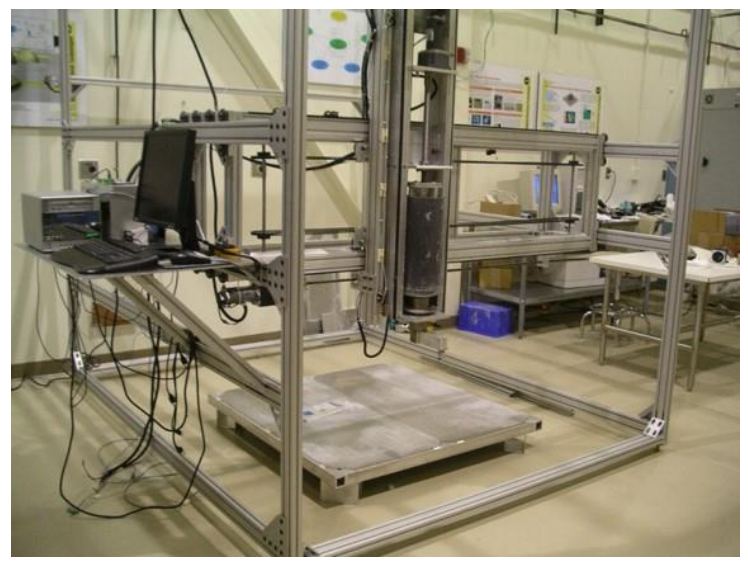

Figure 1. MSFC's Contour Crafting Additive Construction apparatus 
The ACME project builds on MSFC's experience with Additive Construction, initiated in 2004 in a joint project with USC [2]. That effort focused on the development of "waterless" concrete with sulfur as a binder and minimally processed lunar regolith as aggregate, whereas previous lunar concrete studies [3] were concentrated on using Portland Cement (PC) and water as the binder (either directly or in a steam injection method). Extrusion of sulfur-based lunar concrete was successfully demonstrated at USC, but the use of sulfur has several drawbacks that still need to be overcome, including sulfur sublimation, thermal limitations, etc.

Based on the availability of natural resources on both the Moon and Mars, the ACME project is evaluating several cement materials for Additive Construction, including PC, sulfur, and magnesium oxide-based cements including $\mathrm{MgO} / \mathrm{MgCl}_{2}$ (Sorel Cement), and $\mathrm{MgO} / \mathrm{KH}_{2} \mathrm{PO}_{4}$ monopotassium phosphate (MKP).

This paper will summarize these activities to date, planned concrete evaluations, and describe future planned development activities at MSFC on the ACME project.
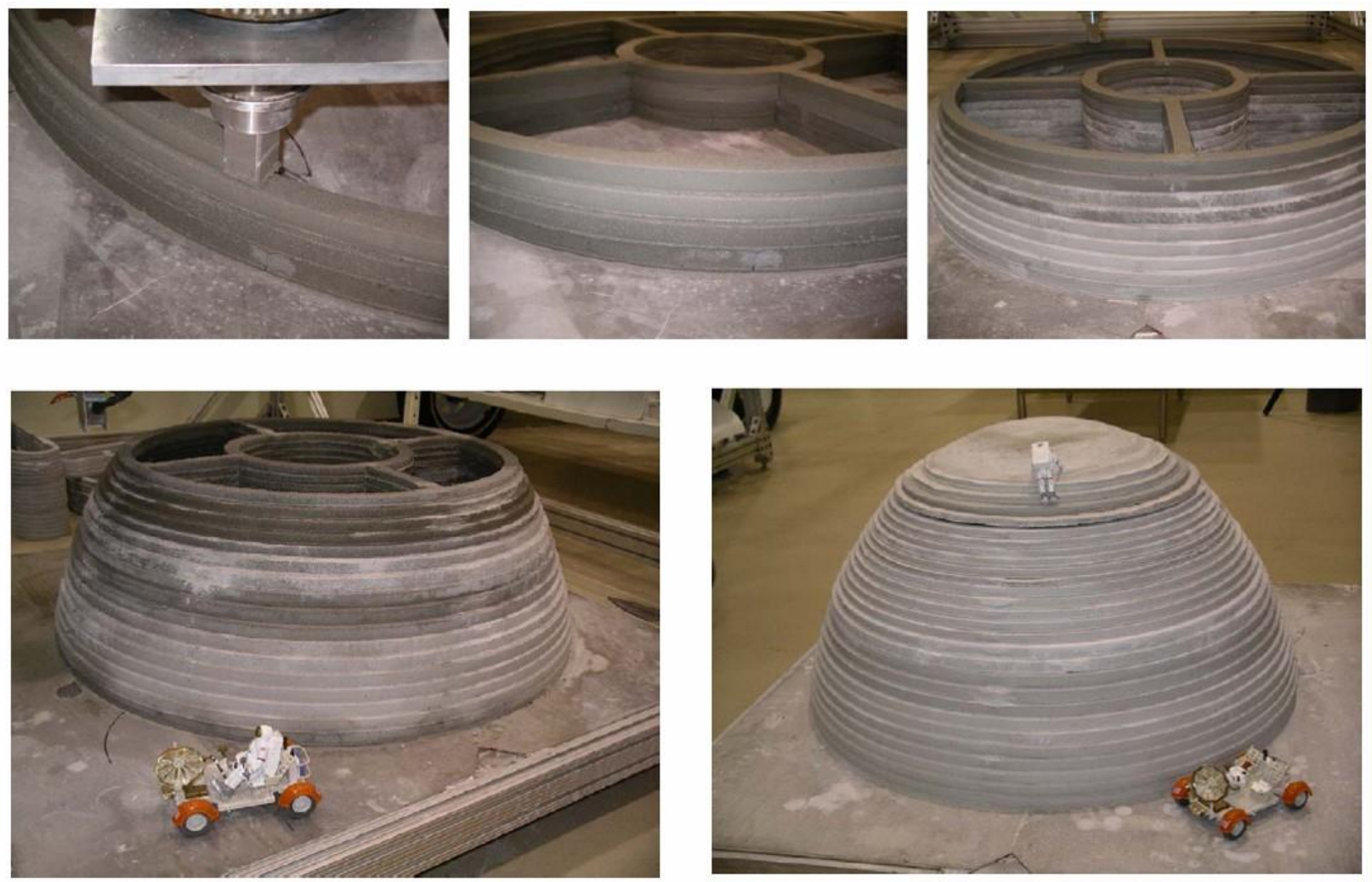

Figure 2 - Dome Structure With Interior Walls Built at MSFC

\section{LUNAR/MARTIAN RAW MATERIALS FOR CONSTRUCTION}

There are three different types of cements under investigation for ACME:

1. Portland cement (most common type used on Earth)

2. Sorel-type cement (magnesium oxide-based) 


\section{Sulfur cement}

Each cement can be manufactured on the surface of Mars (more limited to Sorel-type and sulfur cement on the Moon) either from mining specific minerals or from the extraction of certain metal oxides from the in-situ resources. The potential areas from which the minerals or elements can be obtained are discussed.

\section{Portland cement}

Portland cement is composed primarily of $\mathrm{Ca}, \mathrm{Si}, \mathrm{Al}, \mathrm{Fe}, \mathrm{O}$, and $\mathrm{H}$. Common terrestrial rock types used to create this type of cement are limestone, shale, slate, and sand; mineral phases include calcite $\left(\mathrm{CaCO}_{3}\right)$, clay (variable composition, source of $\mathrm{Fe}, \mathrm{Mg}, \mathrm{Al}, \mathrm{Si}$, and $\mathrm{OH}^{-}$), gypsum $\left(\mathrm{CaSO}_{4} \cdot 2 \mathrm{H}_{2} \mathrm{O}\right)$, and hematite $\left(\mathrm{Fe}_{2} \mathrm{O}_{3}\right)$. Since carbonates are a key component of this type of cement, it is unlikely the cement could easily be produced on the Moon.

\section{Calcium carbonate source}

Large sources of carbonates, such as limestones on Earth, have not been identified on Mars. An outcrop in Columbia Hills (Gusev Crater) was detected by the Mars Exploration Rover (MER) Spirit to have between 16 and 34 weight percent carbonates; the Phoenix lander showed a soil composition containing 3-6 weight percent carbonates [4]. Carbonate globules were also found in the Allan Hills 84001 martian meteorite [5; 6; 7]. These particular carbonates include Ca, Fe, and Mg-rich carbonates. A map of the carbonate-bearing locations, including the Spirit and Phoenix landing sites, is show in [4]; the primary location of $\mathrm{Mg}$ and $\mathrm{Ca}, \mathrm{Fe}$ carbonates is Isidis Planitia and Syrtis Major terranes.

Clay source

The Mars Reconnaissance Orbiter Compact Reconnaissance Imaging Spectrometer for Mars detected phyllosilicates in Endeavour crater; this detection was confirmed on the ground by the Mars Exploration Rover (MER) Opportunity [8]. These phyllosilicates are from the smectite group of clays $(1 / 2 \mathrm{Ca}, \mathrm{Na})_{0} \cdot 7(\mathrm{Al}, \mathrm{Mg}, \mathrm{Fe})_{4}\left[(\mathrm{Si}, \mathrm{Al})_{8} \mathrm{O}_{20}\right](\mathrm{OH})_{4} \bullet \mathrm{nH}_{2} \mathrm{O}$. Evidence for kaolinitesmectite mixed and end-member layers on the martian surface was presented in [9] at Nili Fossae, Mawrth Vallis, and Leighton Crater. Calcinated kaolin and smectite clays are used in the formation of Portland cement on Earth [10].

\section{Sulfate source}

Hydrated sulfates were also identified in Mars Reconnaissance Orbiter data, and confirmed present by Opportunity [8]. These are not gypsum; they are likely hexahydrite $\left(\mathrm{MgSO}_{4} \bullet 6 \mathrm{H}_{2} \mathrm{O}\right)$ or ferrous sulfate (e.g., jarosite). Gypsum was identified using the Mars Express Observatoire pour la Mineralogie, l'Eau, les Glaces, et l'Activite instrument in Juventae Chasma [11]. Jarosite is a hydrous potassium iron sulfate; it has been located at Meridiani Planum (Klingelhöfer et al., 2004) and Mawrth Vallis [12].

Hematite source

Hematite was detected in Meridiani Planum by the Mars Global Surveyor [13]. The MER Opportunity confirmed this detection $[14 ; 8]$. 


\section{Sorel Cement}

Magnesium is a prevalent element on the martian and lunar surfaces. It can be mined using ionic liquids or other extraction techniques. Magnesium chloride $\left(\mathrm{MgCl}_{2}\right)$ or monopotassium phosphate $\left(\mathrm{KH}_{2} \mathrm{PO}_{4}\right)$ are needed to complete the cementation process. On the Moon, chloride ions are commonly available in apatite minerals. Potassium and phosphorous can be found in KREEP (potassium, rare earth elements, and phosphorous) materials. Phosphate minerals on the Moon include apatite, whitlockite/merrillite and keiviite. On Mars, chloride is found in brines or brine deposits [15] and phases such as apatite and amphibole [16] and is noted to be enriched in the strata of Endurance Crater [17] Materials from which chlorine can be mined are found in a wide variety of locations on the martian surface. Potassium is present in jarosite, some clays and micas; these phases have been identified in Meridiani Planum [14] and near Nili Fossae [18].

\section{Sulfur Cement}

Sulfur cement requires an aggregate and sulfur. Sulfur can be mined from the sulfate minerals on Mars described above. A discussion of the sulfur cycle on Mars was provided by [19]. Sulfur can also be found on the moon and extracted a number of different ways; a discussion of sources of sulfur on the Moon is captured in [20].

\section{PLANNED CHARACTERIZATION}

Mechanical properties of hardened concrete can be classified into two categories: short-term, or instantaneous properties, and long-term properties. The short-term properties include strength in compression, tension, and shear; and stiffness as measured by modulus of elasticity, all as a function of cure time. The long-term properties can be classified in terms of creep and shrinkage. Other properties of interest to help characterize concrete performance include set time, and viscosity (as measured by slump).

Initial efforts have focused on the development of concretes that have an initial low slump, good formability and a fairly rapid set time so that maximum strength can be obtained prior to the next layer being added to the structure. A suite of aggregate/binder mixes are being evaluated, as shown in Table 1. Typical cubes used for compression testing and hypervelocity impact test targets are shown in Figure 3.

Table 1 - Combinations of Aggregate/Binder Under Evaluation

\begin{tabular}{|c|c|c|}
\hline & \multicolumn{2}{|c|}{ Aggregate } \\
\hline Cement & $\begin{array}{c}\text { Lunar Regolith Simulant } \\
\text { (JSC-1A) }\end{array}$ & $\begin{array}{c}\text { Mars Regolith Simulant } \\
\text { (Mars-1A) }\end{array}$ \\
\hline Portland Cement/Water & MSFC & MSFC \\
\hline Sulfur & MSFC, USC & USC \\
\hline $\mathrm{MgO} / \mathrm{MgCl}_{2} /$ Water & MSFC (Planned) & MSFC \\
\hline $\mathrm{MgO} / \mathrm{MKP} /$ Water & MSFC (Planned) & MSFC \\
\hline
\end{tabular}




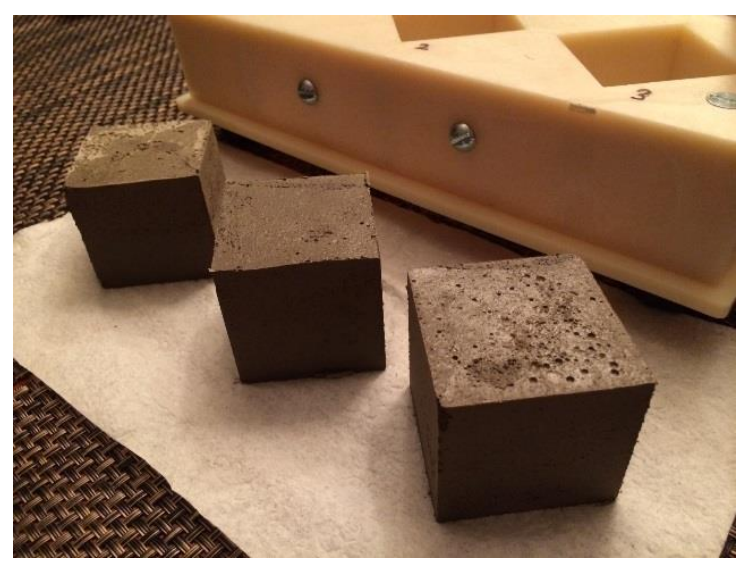

Figure 3 - Concrete Cubes made with Mars-1A Aggregate and MgO/MKP Cement

Full characterization of various concretes will include measurement of compression strength, tensile strength, flexural strength, thermal shock, vacuum stability, and hypervelocity impact testing.

\section{FUTURE ACTIVITIES}

ACME future activities include:

1) Testing segments of printed walls to determine the ability to withstand micrometeorite impact. This testing will be performed at MSFC's Hyper-velocity Impact Test Facility.

2) Continue experimentation to determine the most ideal composition of concrete for both lunar and martian surfaces.

3) Conducting a mobility system trade study to see if the final design should be a large gantry system (such as the contour crafter pictured in Figure 1), a print head mounted on a robotic boom arm, or a cable-mounted system such as those positioning cameras during sporting events.

4) Building and testing the final, full-scale ACME system with enhanced nozzle capabilities including troweling and start-stop shutters. In addition, these systems will incorporate continuous feedstock mixing and delivery systems.

5) Identification and procurement of a martian simulant in large enough quantities to produce full-scale structures.

6) Producing 2D and 3D structures with partner organizations.

7) Preparing for incorporation of this technology into a mission by testing the hardware in relevant environmental conditions (Technology Readiness Level advancement). 


\section{CONCLUSIONS}

The surfaces of the Moon and Mars offer a set of unique resources for development of in situ materials-based structures, including habitats. As part of the ACME project within NASA/MSFC's In-Space Manufacturing (ISM) Initiative, a number of these resources have been and continue to be evaluated. Lunar and martian regolith, as represented by terrestrial simulants, can be used to provide all the materials necessary to make concrete of various compositions. Future efforts will continue to characterize the performance of these materials with respect to continually-developing requirements and will continue to evolve the deposition process as well toward an eventual fullscale implementation.

\section{REFERENCES}

1. Cohen, M.M., and Kennedy, K.J., Habitats and Surface Construction Technology and Development Roadmap. Proceedings of the Government Sponsored Programs on Structures Technology (NASA CP-97-206241), edited by Noor, A. and Malone, J., 1997.

2. Khoshnevis, B., Bodiford, M.P., Burks, K.H., Ethridge, E., Tucker, D., Kim. W., Toutanji, H., and Fiske, M.R. (2005) Lunar Contour Crafting - A Novel Technique for ISRU-Based Habitat Development. Paper AIAA-2005-0538. 43 ${ }^{\text {rd }}$ AIAA Aerospace Sciences Meeting \& Exhibit, Reno, NV, Jan 10-13, 2005.

3. Toutanji, H. (2004) Strength and Durability Performance of Waterless Lunar Concrete. Proceedings: 43 ${ }^{\text {rd }}$ AIAA Aerospace Sciences Meeting, Reno, NV, January 2004.

4. Niles P.B., Catling D. C., Berger G., Chassefiere E., Ehlmann B. L., Michalski J. R., Morris R., Ruff S.W., and Sutter B. (2012) Geochemistry of carbonates on Mars: Implications for climate history and nature of aqueous environments. Space Science Review, doi: 10.1007/s11214-012-9940-y.

5. Mittlefehldt D. W. (1994) ALH84001, a cumulate orthopyroxenite member of the martian meteorite clan. Meteoritics 29, 214-221.

6. Trieman A. H. (1995) A petrographic history of martian meteorite ALH84001: Two shocks and an ancient age. Meteoritics 30, 294-302.

7. Harvey R. P., and McSween H. Y. (1996) A possible high-temperature origin for the carbonates in the martian meteorite ALH84001. Nature 382, 49-51.

8. Wray J. J., Noe Dobrea E. Z., Arvidson R. E., Wiseman S. M., Squyres S. W., McEwen A. S., Mustard J. F., and Murchie S. L. (2009) Phyllosilicates and sulfates at Endeavour Crater, Meridiani Planum, Mars. Geophysical Research Letters 36, L21201, doi:

10.1029/2009GL040734. 
9. Cuadros J., and Michalski J. R. (2013) Investigation of Al-rich clays on Mars: Evidence for kaolinite-smectite mixed-layer versus mixture of end-member phases. Icarus 222, 1, 296-306.

10. Reeves G. M., Sims I., and Cripps J. C. (2006) Clay Materials Used in Construction. Geological Society of London. 525p.

11. Bibring J.P., Langevin Y., Gendrin A., Gondet B., Poulet F., Berthe M., Soufflot A., Arvidson R., Mangold N., Mustard J., Drossart P., and the OMEGA team (2005) Mars surface diversity as revealed by the OMEGA/Mars Express observations. Science 307, $1576-1581$.

12. Farrand W. H., Glotch T. D., Rice Jr. J. W., Hurowitz J. A., and Swayze G. A. (2009) Discovery of jarosite within the Mawrth Vallis region of Mars: Implications for the geologic history of the region. Icarus 204, 478-488.

13. Christensen P. R., Bandfield J. L., Clark R. N., Edgett K. S., Hamilton V. E., Hoefen T., Kieffer H. H., Kuzmin R. O., Lane M. D., Malin M. C., Morris R. V., Pearl J. C., Pearson R., Roush T. L., Ruff S. W., and Smith M. D. (2000) Detection of crystalline hematite mineralization on Mars by the Thermal Emission Spectrometer: Evidence for nearsurface water. Journal of Geophysical Research 105, E4, 9623-9642.doi: 10.1029/1999JE001093.

14. Klingelhöfer G., Morris R. V., Bernhardt B., Schröder C., Rodionov D. S., de Souza Jr. P.A., Yen A., Gellert R., Evlanov E. N., Zubkov B., Foh J., Bonnes U., Kankeleit E., Gütlich P., Ming D. W., Renz F., Wdowiak T., Squyres S. W., and Arvidson R. E. (2004) Jarosite and hematite at Meridiani Planum from Opportunity's Mössbauer Spectrometer. Science 306, 1740-1745.

15. Osterloo M. M., Hamilton V. E., Bandfield J. L., Glotch T. D., Baldridge A. M., Christensen P. R., Tornabene L. L., and Anderson F. S. (2008) Chloride-bearing materials in the southern highlands of Mars. Science 319, 1651-1654.

16. Filiberto J. and Treiman A. H. (2009) Martian magmas contained abundant chlorine, but little water. Geology, doi:10.1130/G30488A.1

17. Gellert R., Clark III B.C., and the MSL and MER Science Teams (2015) In situ compositional measurements of rocks and soils with the Alpha Particle X-ray Spectrometer on NASA's Mars rovers. Elements 11, 39-44.

18. Ehlmann B. L., Mustard J. F., Swayze G. A., Clark R. N., Bishop J. L., Poulet F., Des Marais D. J., Roach L. H., Milliken R. E., Wray J. J., Barnouin-Jha O., and Murchie S. L. (2009) Identification of hydrated silicate minerals on Mars using MRO-CRISM: Geologic context near Nili Fossae and implications for aqueous alteration. Journal of Geophysical Research Planets 114 E2, doi: 10.1029/2009JE003339. 
19. King P. L., and McLennan S. M. (2010) Sulfur on Mars. Elements 6, 107-112.

20. Vaniman D., Pettit D., Heiken G. (1992) Uses of lunar sulfur. The Second Conference on Lunar Bases and Space Activities of the $21^{\text {st }}$ Century, Volume 2, 429-435. 